\title{
Adoption of the concept of person-centred care into discourse in Europe: a systematic literature review
}

\author{
Kristina Rosengren, Petra Brannefors and Eric Carlstrom \\ Institute of Health and Care Sciences, University of Gothenburg, \\ Goteborg, Sweden
}

\begin{abstract}
Purpose - This study aims to describe how person-centred care, as a concept, has been adopted into discourse in 23 European countries in relation to their healthcare systems (Beveridge, Bismarck, out of pocket).

Design/methodology/approach - A literature review inspired by the SPICE model, using both scientific studies (CINHAL, Medline, Scopus) and grey literature (Google), was conducted. A total of 1,194 documents from CINHAL $(n=139)$, Medline $(n=245)$, Scopus $(n=493)$ and Google $(n=317)$ were analysed for content and scope of person-centred care in each country. Countries were grouped based on healthcare systems.

Findings - Results from descriptive statistics (percentage, range) revealed that person-centred care was most common in the United Kingdom $(n=481,40.3 \%)$, Sweden $(n=231,19.3 \%)$, the Netherlands $(n=80,6.7 \%)$, Northern Ireland $(n=79,6.6 \%)$ and Norway $(n=61,5.1 \%)$ compared with Poland $(0.6 \%)$, Hungary $(0.5 \%)$, Greece $(0.4 \%)$, Latvia $(0.4 \%)$ and Serbia $(0 \%)$. Based on healthcare systems, seven out of ten countries with the Beveridge model used person-centred care backed by scientific literature $(n=999)$, as opposed to the Bismarck model, which was mostly supported by grey literature $(n=190)$.

Practical implications - Adoption of the concept of person-centred care into discourse requires a systematic approach at the national (politicians), regional (guidelines) and local (specific healthcare settings) levels visualised by decision-making to establish a well-integrated phenomenon in Europe.

Social implications - Evidence-based knowledge as well as national regulations regarding person-centred care are important tools to motivate the adoption of person-centred care in clinical practice. This could be expressed by decision-making at the macro (law, mission) level, which guides the meso (policies) and micro (routines) levels to adopt the scope and content of person-centred care in clinical practice. However, healthcare systems (Beveridge, Bismarck and out-of-pocket) have different structures and missions owing to ethical approaches. The quality of healthcare supported by evidence-based knowledge enables the establishment of a well-integrated phenomenon in European healthcare.

Originality/value - Our findings clarify those countries using the Beveridge healthcare model rank higher on accepting/adopting the concept of person-centered care in discourse. To adopt the concept of person-centred care in discourse requires a systematic approach at all levels in the organisation - from the national (politicians) and regional (guideline) to the local (specific healthcare settings) levels of healthcare.
\end{abstract}

Keywords Beveridge, Bismarck, Europe, Evidence-based, Literature review, Person-centred care

Paper type Research paper

(C) Kristina Rosengren, Petra Brannefors and Eric Carlstrom. Published by Emerald Publishing Limited. This article is published under the Creative Commons Attribution (CC BY 4.0) licence. Anyone may reproduce, distribute, translate and create derivative works of this article (for both commercial and noncommercial purposes), subject to full attribution to the original publication and authors. The full terms of this licence may be seen at http://creativecommons.org/licences/by/4.0/legalcode

The authors would like to acknowledge University of Gothenburg Centre for Person-Centred Care (GPCC), Sahlgrenska Academy, University of Gothenburg, Gothenburg, Sweden.

Funding: The authors received financial support for the research from the University of Gothenburg Centre for Person-Centred Care (GPCC), Sahlgrenska Academy, Sweden.

Declaration of conflicting interests: The authors declared no potential conflicts of interest with respect to the research, authorship, and/or publication of this article.

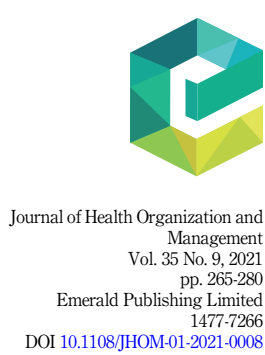


JHOM

35,9

266

\section{Background}

Previous research has highlighted the importance of healthcare organisation, content of healthcare curriculum and financial systems used in healthcare (Chenoweth et al., 2019; Gyllensten et al., 2019; Pirhonen et al., 2017, 2019; Rosengren et al., 2018). The traditional model of healthcare is focused on diseases (medicine and natural science) and does not acknowledge patients' resources and abilities to be an expert in their own life based on their lived experiences (CEN, 2020; IAPO, 2020). Risberg et al. (2006) emphasize the bio-medical framework as the dominating paradigm in medicine with epistemological roots in positivism. Such traditional biomedical tradition has been successful in producing useful medical knowledge, but they are not suited for 'soft' medicine like patient experiences or patient-doctor interaction, which are important elements of clinical medicine. According to Ekman et al. (2011, 2015), person-centred care recognises patients as persons with resources and abilities despite their disease. It includes listening to patient narratives, partnership and agreement between patients and healthcare professionals regarding healthcare activities based on patients' lived experiences, and evidence-based practice documented in a health plan (GPCC, 2020). Moreover, research has shown that person-centred care is associated with shorter hospital stays, lower readmission rates, higher quality of care and satisfaction with healthcare (Edvardsson et al., 2011, 2014; Ekman et al., 2011, 2015); Gyllensten et al. (2019), McCance et al. (2013), McCormack et al. (2010), Pirhonen et al. (2019). These advantages have led politicians and policymakers to have an increased interest in adopting and implementing person-centred care (Swedish Agency for Health and Care Services Analysis, 2018a, b). For example, Swedish law (Swedish code of Statutes 2017:30, 2017) promotes inclusion of all citizens in health and well-being and recommends implementation of person-centred care. However, person-centred care is regarded as an unclear concept because of limited knowledge and understanding among healthcare professionals (Lodge et al., 2017; Moore et al., 2017; Naldemirci et al., 2017; Oppert et al., 2018). Therefore, this study highlights areas for improvement, such as the education of healthcare professionals (Rosengren et al., 2018).

Britten et al. (2020) emphasised the use of practical insights from health professionals to facilitate successful clinical work for further adoption and implementation of person-centred care. They argue that research has only focused on the need to adopt and implement personcentred care, instead of actively involving all actors to develop a model of co-creation of care within the team (staff, patients, relatives and managers). Awareness about person-centred care and its effects on quality of health and well-being increase its implementation (Alharbi et al., 2014; Lydahl, 2017). According to Britten et al. (2020), tools such as steering committees (ward managers, chief physicians) and change agents (assistant nurses, registered nurses, physicians) can act as facilitators to educate and implement person-centred care in day-to-day clinical practice. They stress that co-creation of care within the team (bedside) as well as within organisations is the core component to facilitate person-centred care - an ethical framework for improved health and well-being for all involved (patient, relatives, healthcare professionals and managers).

An integrative literature review including research from Australia, New Zealand, Canada, USA and Europe, described that no universally used definition of person-centred care exists. It highlighted three factors to understand and practice person-centred care: people, practice and power (Byrne et al., 2020). The review uncovered a malalignment between the concept of person-centred care and its operationalisation at the micro, meso and macro levels of the healthcare system. To our knowledge, the diffusion of person-centred care in Europe is still unknown, and it is unclear if the main construction of healthcare systems coincides with the occurrence of person-centred care. Therefore, this study aims to describe how person-centred care, as a concept, has been adopted into discourse in 23 European countries in relation to their healthcare systems (Beveridge, Bismarck, out of pocket). 
A systematic literature review (Bettany-Saltikov and McSherry, 2016) inspired by the SPICE model (Booth, 2004), including scientific (CINHAL, Medline, Scopus) and grey literature (Google), was used to describe the extent of person-centred care (scope and content) in Europe.

\subsection{Data collection}

To ensure variation of countries based on healthcare systems (Beveridge model, Bismarck model and out of pocket model) and localisation in Europe, the following countries were included: Belgium, Czech Republic, Denmark, Estonia, Finland, France, Germany, Greece, Hungary, Iceland, Ireland, Italy, Latvia, Malta, Norway, Poland, Portugal, Serbia, Slovenia, Spain, Sweden, the Netherlands and United Kingdom and the UK (England, Scotland, Wales, North Ireland). One inclusion criterion was the study of equal parts of the common healthcare systems. However, European countries practicing the main healthcare systems were unequal, resulting in inclusion of unequal number of healthcare systems-Beveridge model $(n=12)$, $\operatorname{Bismarck}$ model $(n=10)$ and out of pocket model $(n=1)$. Former Eastern European countries were difficult to assort to the main healthcare systems. Another inclusion criterion was to include all parts of Europe, from the north, west and east to the Mediterranean area. Grey literature from Google and scientific literature published in peer-reviewed journals, citied in CINHAL, Medline or Scopus databases, between January 2010 and May 2020, from the above countries, containing the term "person-centred care" were included in the study. Exclusion criteria were papers written in a language other than English or Swedish and the use of words like person-centred care such as client-centred, medical-centred, family centred, patientcentred and people-centred care (Table 1).

Literature was collected in four stages (Figure 1a-1d): identification of data (searching), screening of titles and abstracts to ensure that they met the inclusion criteria, discussion about eligibility and inclusion of data in the current study (Bettany-Saltikov and McSherry, 2016). Suitable keywords ("person-centred", "person-centred”, "person-centred”, "personcentred", "person-centred", "person centeredness", "personcenteredness", or "person centeredness") for different databases (CINHAL, Medline, Scopus, Google) were identified. Data collection was conducted from November 2019 to May 2020 (CINHAL, $n=1,601$; Medline, $n=1,537$; Scopus, $n=1,104$; Google, $n=205,933,000)$. Titles and abstracts were screened for aim and inclusion and exclusion criteria (CINHAL, $n=1,299$; Medline, $n=1,532$; Scopus, $n=1,076$; Google, $n=205,931,878$ ). Thereafter, selected documents (CINHAL, $n=206$; Medline, $n=373$; Scopus, $n=674$; Google, $n=1,671$ ) were screened and 1,194

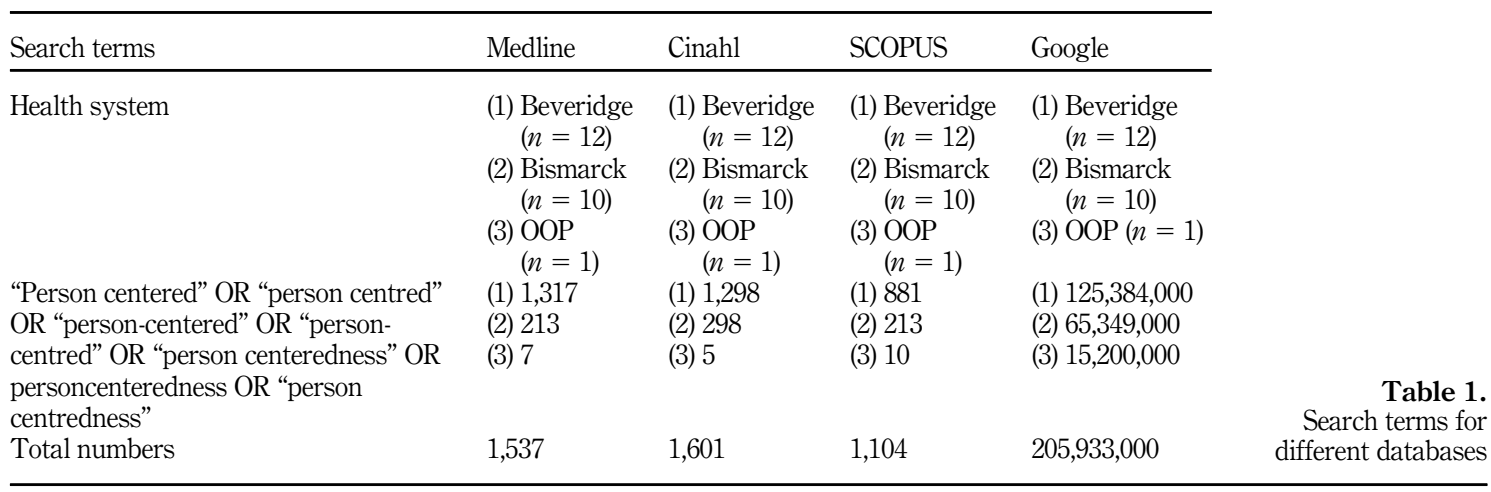


JHOM

35,9

\section{8}

Figure 1.

Search strategy and screening procedure according to SPICE
PRISMA 2009 Flow Diagram (Cinahl, Medline, Scopus, Google)
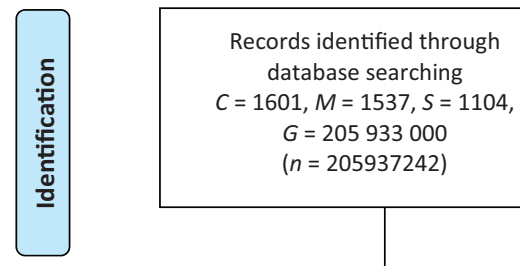

Records identified through database searching

$C=1601, M=1537, S=1104$,

$G=205933000$

( $n=205937242)$
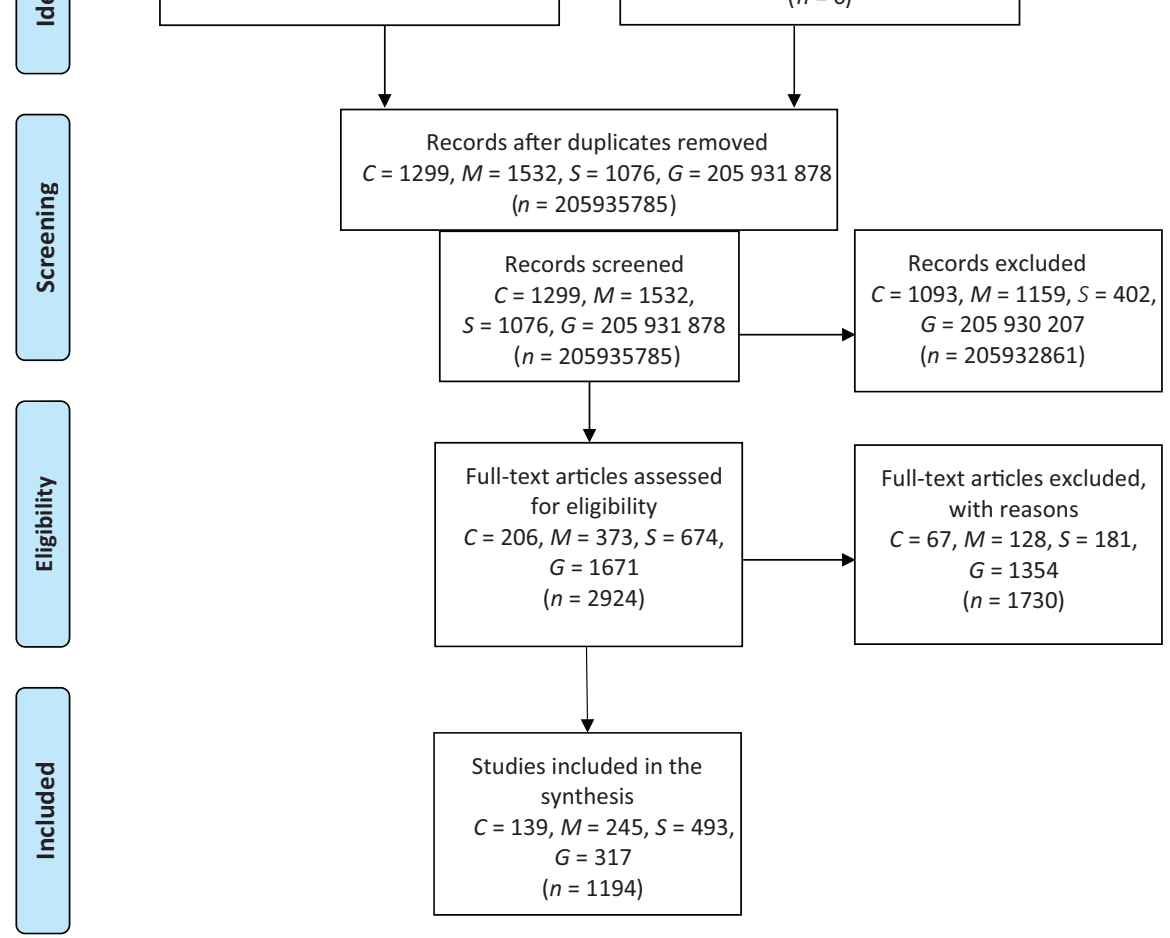

Additional records identified through other sources $(n=0)$

ull-text articles assessed with reasons $G=1354$

$(n=1730)$

documents were omitted (CINHAL, $n=139$; Medline, $n=245$; Scopus, $n=493$; Google, $n=317$ ).

\subsection{Data analysis}

The included literature (scientific/grey literature) from four databases (CINHAL, Medline, Scopus, Google) were analysed for content and scope of person-centred care in each country. Countries were grouped based on their specific healthcare systems (Beveridge, Bismarck, out of pocket) and geographic placement. Descriptive analysis (Polit and Beck, 2017) was conducted for range (1-23), percentages $(0 \%-100 \%)$ and valuation (5-point scale). Data from scientific (CINHAL, Medline, Scopus) and public literature (Google) were analysed using the following steps: (1) obtaining an overview of data regarding how person-centred care, as content, has been adopted in discourse; (2) data were analysed in parts (country and 
healthcare system), and the extent of person-centred care in relation to specific countries' healthcare systems were described within the included literature (CINHAL, Medline, Scopus and Google); (3) data were valued on a 5-point scale ( 1 = person-centred care is emphasised as something that needs to be established, 2 = thereafter person-centred care is going to be established in the country, 3 = person-centred care is an established phenomenon in some areas but not in others, $4=$ person-centred care is established as a phenomenon, but improvements are needed within the country, $5=$ person-centred care is well integrated in

healthcare) in included documents (scientific, public) and (4) results are presented based on how the concept of person-centred care has been adopted into discourse based on different European countries' geographic placement and healthcare system (Beveridge, Bismarck, out of pocket).

\subsection{Ethical considerations}

The current systematic review is grounded in high ethical standards by following the ethical guidelines for human and social research (Codex, 2020). All included data, especially data from scientific literature (CINHAL, Medline, Scopus), were assessed with respect to ethical considerations such as information, voluntariness and confidentiality to do no harm; to improve health and well-being (Codex, 2020). Moreover, well-established scientific methods (systematic review and descriptive analysis) have been used to conduct scientifically sound studies (Bettany-Saltikov and McSherry, 2016; Polit and Beck, 2017).

\section{Findings}

The results are presented by country, grouped by respective healthcare systems (Beveridge, Bismarck, out of pocket) and their geographic placement in Europe.

The most relevant content and scope of person-centred care was found in the UK $(n=481$, $40.3 \%$ of all literature), followed by Sweden $(n=231,19.3 \%)$. Thereafter, available literature dropped for the following 21 countries: the Netherlands $(n=80,6.7 \%)$, Ireland $(n=79,6.6 \%)$ and Norway $(n=61,5.1 \%)$. The remaining 18 countries (6-23) included 40 documents or less (Table 2) within the scope of person-centred care. The bottom five countries include Poland $(0.6 \%)$, Hungary $(0.5 \%)$, Greece $(0.4 \%)$, Latvia $(0.4 \%)$ and Serbia $(0 \%)$. Moreover, the most frequently used databases for person-centred care was Scopus (41.3\%), followed by Google (26.5\%), Medline (20.5\%) and CINHAL (11.6\%) (Table 2).

Furthermore, in countries with the Beveridge healthcare system $(12 / 23=0.5217,52.2 \%)$, the term "person-centred care" was used in $85 \%$ of the papers (Google $=81 \%$, CINHAL $=94 \%)$. Conflicting results were observed for countries with the Bismarck healthcare system $(10 / 23=0.4347,43.5 \%)$. The term "person-centred care" was used in $15 \%$ of the papers (CINHAL $=6 \%$, Google $=18 \%$ ). In countries with an out-of-pocket healthcare system, only Greece was included (4\%) and resulted in $0.4 \%$ use of person-centred care (less scientific literature, Table 3).

Another way of presenting how common person-centred care is in the included countries, is by grouping them according to their geographic location (east, north, south and west). Person-centred care is the most common $(50.6 \%)$ in the west of UK (England, Northern Ireland, Scotland, Wales) and Ireland; second (27.5\%) in the north of Scandinavian countries (Sweden, Norway, Denmark, Finland, Iceland), followed by central Europe $(11 \%$; the Netherlands, Germany, Belgium), south (8\%) of Europe (Spain, Italy, Malta, Portugal, France, Slovenia, Greece and Serbia) and finally in the east of Europe (3\%; Estonia, Czech Republic, Poland, Hungary, Latvia).

Moreover, the included countries $(n=23)$ varied in the number of documents, content and scope of person-centred care, which were valued on a 5-point scale as follows: (1) personcentred care is emphasised as something that needs to be established; (2) person-centred care 
JHOM

35,9

270

\begin{tabular}{|c|c|c|c|c|c|}
\hline Countries & $\begin{array}{c}\text { Scopus } \\
n=493 \\
41.3 \%\end{array}$ & $\begin{array}{c}\text { Google } \\
n=317 \\
26.5 \%\end{array}$ & $\begin{array}{c}\text { Medline } \\
n=245 \\
20.5 \%\end{array}$ & $\begin{array}{c}\text { Cinahl } \\
n=139 \\
11.6 \%\end{array}$ & $\begin{array}{c}\text { Total } \\
N=1,194 \\
100 \%\end{array}$ \\
\hline 1. UK (England, Scotland, Wales, North Ireland) & 168 & 148 & 90 & 75 & $\begin{array}{c}481 / 1,194 \\
40.3 \%\end{array}$ \\
\hline 2. Sweden & 119 & 12 & 68 & 32 & $\begin{array}{c}231 / 1,194 \\
19.3 \%\end{array}$ \\
\hline 3. The Netherlands & 40 & 16 & 18 & 6 & $\begin{array}{c}80 / 1,194 \\
6.7 \%\end{array}$ \\
\hline 4. Ireland & 33 & 22 & 15 & 9 & $\begin{array}{c}79 / 1,194 \\
6.6 \%\end{array}$ \\
\hline 5. Norway & 36 & 9 & 14 & 2 & $\begin{array}{c}61 / 1,194 \\
5.1 \%\end{array}$ \\
\hline 6. Germany & 22 & 5 & 13 & 0 & $\begin{array}{c}40 / 1,194 \\
3.4 \%\end{array}$ \\
\hline 7. Spain & 15 & 6 & 9 & 5 & $\begin{array}{c}35 / 1,194 \\
2.9 \%\end{array}$ \\
\hline 8. Denmark & 11 & 9 & 7 & 4 & $\begin{array}{c}31 / 1,194 \\
2.6 \%\end{array}$ \\
\hline 9. Italy & 11 & 9 & 0 & 0 & $\begin{array}{c}20 / 1,194 \\
1.7 \%\end{array}$ \\
\hline 10. Belgium & 9 & 3 & 5 & 2 & $\begin{array}{c}19 / 1,194 \\
1.6 \%\end{array}$ \\
\hline 11. Finland & 9 & 4 & 1 & 4 & $\begin{array}{c}18 / 1,194 \\
1.5 \%\end{array}$ \\
\hline 12. Portugal & 2 & 13 & 0 & 0 & $\begin{array}{c}15 / 1,194 \\
1.3 \%\end{array}$ \\
\hline 13. Malta & 0 & 14 & 0 & 0 & $\begin{array}{c}14 / 1,194 \\
1.2 \%\end{array}$ \\
\hline 14. Estonia & 2 & 10 & 0 & 0 & $\begin{array}{c}12 / 1,194 \\
1 \%\end{array}$ \\
\hline 15. Iceland & 3 & 5 & 1 & 0 & $\begin{array}{c}9 / 1,194 \\
0.8 \%\end{array}$ \\
\hline 16. Slovenia & 3 & 5 & 1 & 0 & $\begin{array}{c}9 / 1,194 \\
0.8 \%\end{array}$ \\
\hline 17. Czech Republic & 1 & 7 & 1 & 0 & $\begin{array}{c}9 / 1,194 \\
0.8 \%\end{array}$ \\
\hline 18. France & 4 & 3 & 1 & 0 & $\begin{array}{c}8 / 1,194 \\
0.7 \%\end{array}$ \\
\hline 19. Poland & 2 & 4 & 1 & 0 & $\begin{array}{c}7 / 1,194 \\
0.6 \%\end{array}$ \\
\hline 20. Hungary & 1 & 5 & 0 & 0 & $\begin{array}{c}6 / 1,194 \\
0.5 \%\end{array}$ \\
\hline 21. Greece & 2 & 3 & 0 & 0 & $\begin{array}{c}5 / 1,194 \\
0.4 \%\end{array}$ \\
\hline 22. Latvia & 0 & 5 & 0 & 0 & $\begin{array}{c}5 / 1,194 \\
0.4 \%\end{array}$ \\
\hline 23. Serbia & 0 & 0 & 0 & 0 & 0/1,194 \\
\hline
\end{tabular}

is going to be established in the country; (3) person-centred care is an established phenomenon in some areas but not in others; (4) person-centred care is established as a phenomenon and there are improvements within the country; and finally, (5) person-centred care is a well-established phenomenon and well-integrated part of healthcare. Countries with the Beveridge system $(12 / 23=0.52,52 \%)$ used more person-centred care $(7 / 10$ countries $)$ compared with countries with the Bismarck healthcare system (Table 4). 


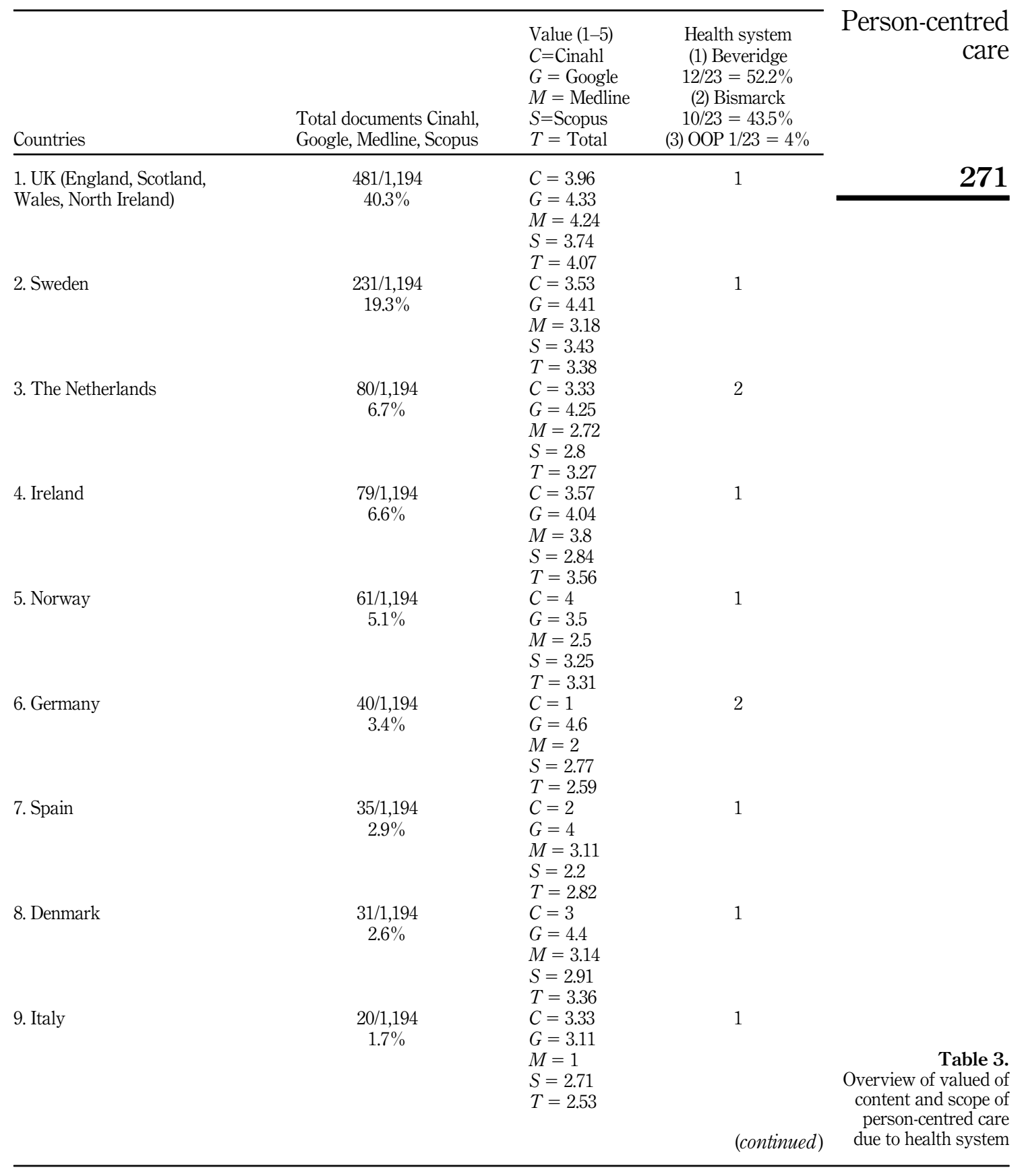


JHOM

35,9

Total documents Cinahl, Google, Medline, Scopus

11. Finland

12. Portugal

13. Malta

14. Estonia

15. Iceland

16. Slovenia

17. Czech Republic

18. France
$19 / 1,194$

$1.6 \%$

$18 / 1,194$

$1.5 \%$

$15 / 1,194$

$1.3 \%$

$14 / 1,194$

$1.2 \%$

$12 / 1,194$

$1 \%$

9/1,194

$0.8 \%$

$9 / 1,194$

$0.8 \%$

$9 / 1,194$

$0.8 \%$

$8 / 1,194$

$0.7 \%$
Value (1-5)

$C=$ Cinahl

$G=$ Google

$M=$ Medline

$S=$ Scopus

$T=$ Total

$C=2.5$

$G=5$

$M=3$

$S=2.11$

$T=3.15$

$C=3,5$

$G=4$

$M=5$

$S=3.11$

$T=3.9$

$C=1$

$G=3.92$

$M=1$

$S=3$

$T=2.23$

$C=3.33$

$G=4.28$

$M=1$

$S=1$

$T=2.4$

$C=1$

$G=3.7$

$M=0$

$S=1.5$

$T=1.55$

$C=1$

$G=4.5$

$M=4$

$S=2.33$

$T=2.95$

$C=3.33$

$G=3.6$

$M=2$

$S=2.66$

$T=2.89$

$C=1$

$G=3.42$

$M=2$

$S=2$

$T=2.10$

$C=1$

$G=4$

$M=3.5$

$S=3.25$

$T=2.94$
Health system

(1) Beveridge

$12 / 23=52.2 \%$

(2) Bismarck

$10 / 23=43.5 \%$

(3) $\mathrm{OOP} 1 / 23=4 \%$
2

1

1

1

2

1

2

2

2

(continued)

Table 3. 


\begin{tabular}{|c|c|c|c|c|}
\hline Countries & $\begin{array}{l}\text { Total documents Cinahl, } \\
\text { Google, Medline, Scopus }\end{array}$ & $\begin{array}{l}\text { Value }(1-5) \\
C=\text { Cinahl } \\
G=\text { Google } \\
M=\text { Medline } \\
S=\text { Scopus } \\
T=\text { Total }\end{array}$ & 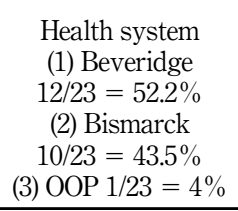 & $\begin{array}{r}\text { Person-centred } \\
\text { care }\end{array}$ \\
\hline 19. Poland & $\begin{array}{c}7 / 1,194 \\
0.6 \%\end{array}$ & $\begin{array}{l}C=3.33 \\
G=3 \\
M=2 \\
S=3.5 \\
T=2.96\end{array}$ & 2 & 273 \\
\hline 20. Hungary & $\begin{array}{c}6 / 1,194 \\
0.5 \%\end{array}$ & $\begin{array}{l}C=0 \\
G=4.25 \\
M=1 \\
S=3 \\
T=2.06\end{array}$ & 2 & \\
\hline 21. Greece & $\begin{array}{c}5 / 1,194 \\
0.4 \%\end{array}$ & $\begin{array}{l}C=0 \\
G=5 \\
M=1 \\
S=3 \\
T=2.25\end{array}$ & 3 & \\
\hline 22. Latvia & $\begin{array}{c}5 / 1,194 \\
0.4 \%\end{array}$ & $\begin{array}{l}C=0 \\
G=2.2 \\
M=0 \\
S=0 \\
T=0.55\end{array}$ & 1 & \\
\hline 23. Serbia & $0 / 1,194$ & 0 & 2 & \\
\hline Total & 1,194 & 2.64 & $\begin{array}{c}\text { (1) } 2.92(0.55-4.07) \\
n=999 / 12 \\
\text { (2) } 2.35(0-3.27) \\
n=190 / 10 \\
\text { (3) } 2.25 n=5 / 1\end{array}$ & Table 3. \\
\hline
\end{tabular}

The highest number of documents available on the content and scope of person-centred care was found for the UK (England, Scotland, Wales and Northern Ireland), with a value of 4.35 (1-5), for the establishment of person-centred care, followed by Sweden (4.42; Table 4). The Netherlands (2.95) was placed third with two other countries within the Bismarck system (3/ 10 countries, $30 \%$ ). Germany (2.38) placed sixth, and Belgium (2.53) tenth. Lesser documents (PCC) were found in other countries, seven out of ten countries within the Bismarck system (Estonia at place 14; Slovenia, 16; Czech Republic, 17; France, 18; Poland, 19; Hungary, 20 and Serbia, 23), two countries with the Beveridge system (Iceland at place 15, Latvia at 22) and Greece (place 21) with the out-of-pocket healthcare system (Table 4).

\section{Discussion}

The current study describes the extent of person-centred care in 23 European countries in relation to their healthcare systems (Beveridge, Bismarck and out of pocket). The main difference in using the concept of person-centred care in research and grey literature was that between Beveridge and Bismarck healthcare models. In literature and documents, this concept appeared more frequently in countries using the Beveridge model than the Bismarck model. Or et al. (2010) suggest that the main differences in underlying values are universality and equity in countries with the Beveridge model versus plurality, 


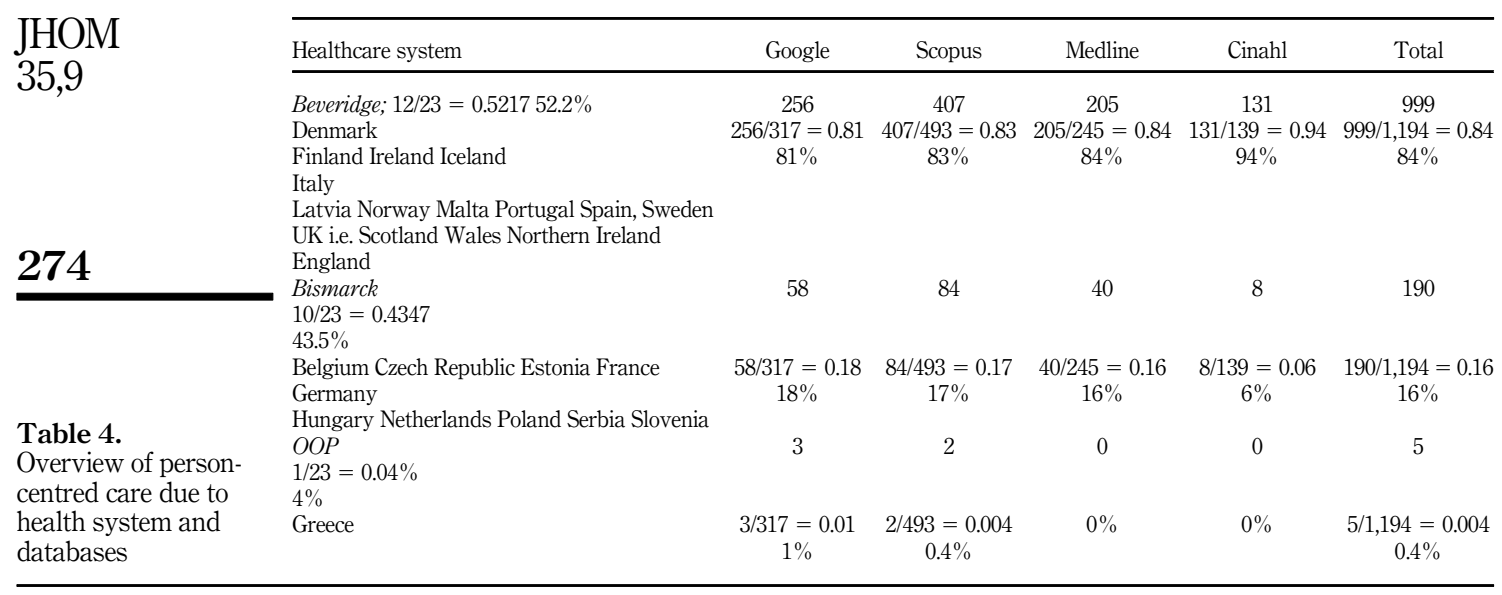

liberty and solidarity in countries with the Bismarck model. Even if the Beveridge type of healthcare is available for all inhabitants, the possibility of making choices is limited, while the Bismarck model offers a variety of providers, but the distribution of healthcare is not always equal (Torbica et al., 2018). This can be illustrated by the Boehm models (European Council on Foreign Relations, 2020), where countries are categorised by state societal and private degrees of control over regulation, financing and provision of healthcare. In Figure 2, green and dark pink illustrate insurance systems (mainly Bismarck), while medium pink illustrates the types of national health services (mainly Beveridge).

The results show that person-centred care was most adopted into discourse in the UK (England, Scotland, Wales and Northern Ireland), followed by Sweden, the Netherlands, Ireland and Norway, compared with Poland, Hungary, Greece, Latvia and Serbia. Moreover, seven out of ten countries with the Beveridge model used the concept of person-centred care in scientific literature, as opposed to the Bismarck model, where the concept was mostly supported by grey literature. Since only Greece (placed 21) practices an out-of-pocket healthcare system, it is difficult to draw conclusions regarding the scope and content of person-centred care in relation to this healthcare system.

The Beveridge healthcare system shows the majority using the concept of person-centred care $(84 \%$ vs. $16 \%)$ compared with the Bismarck healthcare system, which has a variation of scope and content of person-centred care, based on geographic locations (east, north, south and west) of the European countries included in this study. Since person-centred care is seen in $40.3 \%$ of the documents available for Western European countries (the UK and Ireland), it can be considered an established and well-integrated phenomenon, especially in areas of elderly care (McCormack et al., 2010). Similar results were observed for some of the Scandinavian countries, such as Sweden (19.3\%). However, this result is lower for Northern Europe, Norway $(5.1 \%)$, Denmark $(2.6 \%)$, Finland $(1.5 \%)$ and Iceland $(0.8 \%)$, and Central Europe, the Netherlands, Germany and Belgium (6.6\%-6.6\%). The following discussion is focused on why there is a variation in adopting the concept of person-centred care: the relationship between person-centred care and healthcare system or vice-versa. One reason could be that in the UK and Sweden, the government decided to implement person-centred care based on evidence-based research regarding the efficiency of this healthcare practice (Edvardsson et al., 2011, 2014; Ekman et al., 2011, 2015; Gyllensten et al., 2019; McCance et al., 2013; McCormack et al., 2010; Pirhonen et al., 2019). Therefore, regulations and laws (e.g. the 


\section{Healthcare Systems Boehm Model}

Healthcare system type

Etatist Social Health Insurance

National Health Insurance

National Health Service

Social Health Insurance

Social-based Mixed System

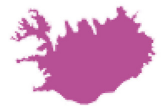

(2020 Mapbox () OpenStreetMap

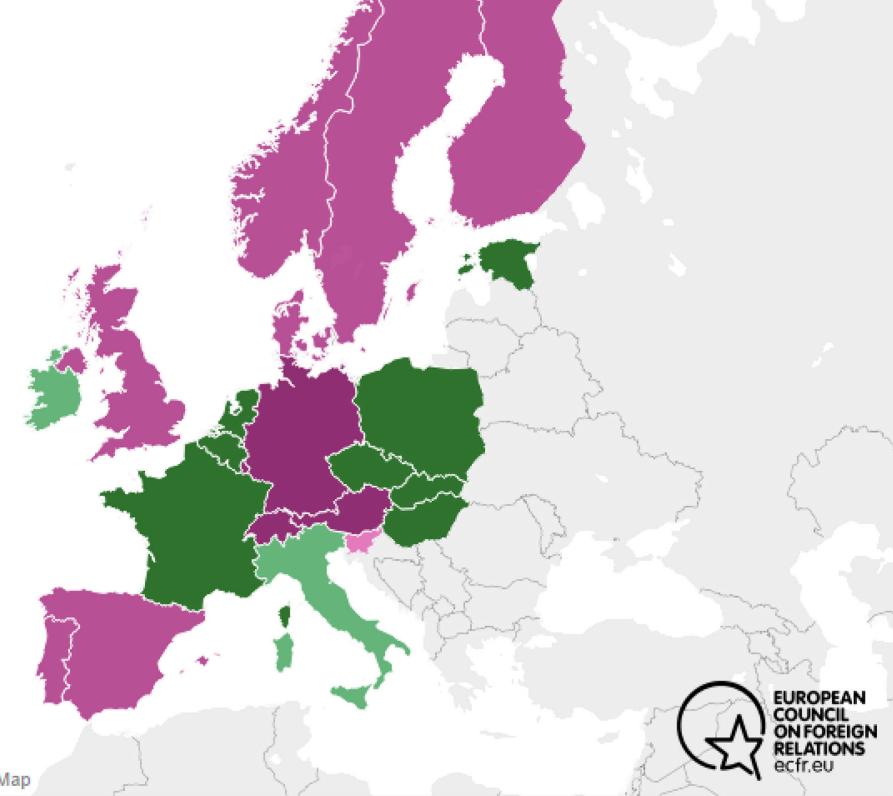

Source(s): Boehm et al.

Countries categorised by state, societal and private degree of control over regulation, financing and provision of healthcare
Person-centred

care

275

Figure 2.

Overview of European countries due to provision of healthcare

Swedish Code of Statutes, 2017:30) focus on shared decision-making in line with personcentred care (GPCC, 2020; Ricoeur, 1992). Moreover, patient unions (IAPO, 2020; OECD, 2017) influence healthcare in favour of acknowledging patients as experts in their own lives through their lived experiences and partners in their own healthcare. This approach is grounded in democracy, covered in international human rights law, and is based on active involvement in health and well-being (UN, 2020).

However, in the south (except Spain) and east of Europe, person-centred care seems to be less common based on the content available. The reasons for this outcome need to be examined in other studies. It may be due to cultural differences in the society and healthcare sectors. Another reason can be difficulties experienced in the rapidly changing processes of the healthcare sector from a Semashko, and post-Semashko-type of healthcare systems in former Eastern Europe (Kaminska et al., 2021).

The current results could also be discussed in relation to public versus private/insurancebased healthcare due to high quality of healthcare, democracy, human rights, as well as committed patient associations and unions, which are in line with the ethical approach of person-centred care (IAPO, 2020; OECD, 2017). Public funded healthcare and taxations are 
$\mathrm{JHOM}$

35,9

used in the UK, Scandinavian countries and Spain - countries ranked higher for adopting the discourse of person-centred care. This could be because healthcare is organised by the government and selected politicians, who make decisions on the framework for specific healthcare settings, such as laws, budgets and goals. Therefore, it is easier to call upon changes because evidence-based knowledge is used as the foundation for developing laws and policies. Moreover, basic democratic assumptions are used at different levels of community/state (OECD, 2017; Swedish Agency for Health and Care Services Analysis, 2018a, b). Participation and shared decision-making are used to influence the quality of care. Person-centred care is one way to improve healthcare, which is in line with research and goals based on patient associations (Alharbi et al., 2014; Britten et al., 2020; IAPO, 2020).

The traditional healthcare model focuses more on patients' disease and reasons behind the occurrence of suffering instead of patients' resources/abilities and health and well-being (Alharbi et al., 2014). The traditional biomedical approach, assume a disease as deviations from quantifiable biological variables of normality. Such an approach is only concerned with organic malfunctions and measurable aspects of illness. However, healthcare professionals need to acknowledge patients as human beings with experiences, desires and wishes, who can take responsibility for their health and well-being. However, healthcare professionals are resistant to these changes. Evidence-based knowledge is an important motivator for improvement in clinical practice (Alharbi et al., 2014; Rosengren, 2016; Wranik, 2012). A systematic approach (Britten et al., 2020) regarding the scope and content of person-centred care (organisational and professional) is one tool that facilitates successful clinical work. Research has focused on the need of healthcare systems to adopt and implement personcentred care; however, research should also focus on co-creation of healthcare (staff, patients, relatives and managers). Evidence-based knowledge regarding high-quality care is important for facilitating changes in the healthcare system. Research (Ekman et al., 2011, 2015; GPCC, 2020) show that listening carefully to patients' narratives and agreement in partnership (between the patient and healthcare professionals) regarding essential matters documented in a health plan, facilitates efficient healthcare (Gyllensten et al., 2019; Pirhonen et al., 2019). A key factor that facilitates knowledge translation and the use of limited resources is co-creation of care as synergy leads to shorter hospital stays, lower readmission rates, higher quality of care and patient satisfaction with healthcare (Edvardsson et al., 2011, 2014; Ekman et al., 2011, 2015; Gyllensten et al., 2019; McCance et al., 2013; McCormack et al., 2010; Pirhonen et al., 2019).

It may be more difficult to adopt and implement innovations such as person-centred care in private/insurance-based healthcare systems because of the autonomous nature of care providers without a common organisational umbrella. For example, Germany has over 200 insurance companies covering healthcare. This could lead to difficulties regarding the national implementation of a specific innovation or care model (Härter et al., 2017). Another reason is that there are independent caregivers in different departments/settings in the public sector. Adoption of person-centred care is possible with systematic frameworks supported by regulations and laws that Britten et al. (2020) highlight, together with co-creation of care between patients, healthcare professionals, managers and politicians. This systematic point of view is supported by strong patient unions as well as evidence-based knowledge developed by research regarding the scope and content of person-centred care, which can be a motivator for the national adoption and implementation of person-centred care.

According to the results, neighbouring countries seem to influence each other (Alharbi et al., 2014) - UK-Ireland, and Scandinavian countries organise healthcare in the same way. For example, the Nordic model is funded by taxes with similarities regarding democratic aspects and the healthcare system-an umbrella that facilitates person-centred care. However, results indicate that person-centred care is an unclear phenomenon among health professionals. Therefore, future research regarding person-centred care needs to focus on 
clinical implications, as well as a systematic point of view when person-centred care is adopted and implemented in healthcare systems across Europe (Britten et al., 2020). The future goal is to increase awareness about how person-centred care can be used in clinical practice to improve health and well-being (Ekman et al., 2011; Røen et al., 2018; Vassbø et al., 2019).

\section{Limitations}

There are limitations to this systematic literature review. First, the term "person-centred care" was used to map person-centred care in different European countries, where the scope and content of person-centred care could be named differently, as mentioned in the exclusion criteria. Therefore, documents could have been lost. Future research should include a wider range of terms. Second, only 23 out of the 49 European countries were included, investigating only a part of the European perspective. Another limitation is that only one country used an out-of-pocket healthcare system; therefore, the overall conclusions regarding this healthcare system are limited. The current study indicates that healthcare systems and geographic placement influence the scientific soundness of research and quality of care (Bettany-Saltikov and McSherry, 2016; Polit and Beck, 2017). However, the current study should consider the above limitations. Future studies are required to confirm these results.

\section{Conclusion}

Our findings clarify those countries using the Beveridge healthcare model rank higher on accepting/adopting the concept of person-centered care in discourse. To adopt the concept of person-centred care in discourse requires a systematic approach at all levels in the organisation-from the national (politicians) and regional (guideline) to the local (specific healthcare settings) levels of healthcare. Evidence-based knowledge as well as national regulations regarding person-centred care are important tools to motivate the adoption of person-centred care in clinical practice. This could be expressed by decision-making at the macro (law, mission) level, which guides the meso (policies) and micro (routines) levels to adopt the scope and content of person-centred care in clinical practice. However, healthcare systems (Beveridge, Bismarck and out-of-pocket) have different structures and missions owing to ethical approaches. The quality of healthcare supported by evidence-based knowledge enables the establishment of a well-integrated phenomenon in European healthcare.

\section{References}

Alharbi, T.S., Olsson, L.E., Ekman, I. and Carlström, E. (2014), "The impact of organizational culture on the outcome of hospital care: after the implementation of person-centred care", Scandinavian Journal of Public Health, Vol. 42, pp. 104-110, doi: 10.1177/1403494813500593.

Bettany-Saltikov, J. and McSherry, R. (2016), How to Do a Systematic Literature Review in Nursing: A Step-by-step Guide, Open University Press, London.

Booth, A. (2004), "Formulating answerable questions", in Booth, A. and Brice, A. (Eds), Evidence Based Practice for Information Professionals: A Handbook, Facet Publishing, London, pp. 61-70.

Britten, N., Ekman, I., Naldemirci, Ö., Javinger, M., Hedman, H. and Wolf, A. (2020), "Learning from Gothenburg model of person-centred healthcare”, BMJ, Vol. 370, m2738, doi: 10.1136/ bmj.m2738.

Byrne, N., Baldwin, A. and Harvey, C. (2020), "Whose centre is it anyway? Defining person-centred care in nursing: an integrative review", PLoS One, Vol. 15, p. e0229923, doi: 10.1371/journal. pone.0229923. 
JHOM 35,9

\section{8}

Chenoweth, L., Stein-Parbury, J., Lapkin, S., Wang, A., Liu, Z., Williams, A. and Ginsberg, S. (2019), "Effects of person-centered care at the organisational-level for people with dementia. A systematic review", PLoS One, Vol. 14, e0212686, doi: 10.1371/journal.pone.0212686.

Codex (2020), "Rules and guidelines for research (Regler och riktlinjer för forskning)", The Humanities and Social Sciences, available at: http://codex.vr.se/en/forskninghumsam.html.

Edvardsson, D., Fetherstonhaugh, D., McAuliffe, L., Nay, R. and Chenco, C. (2011), "Job satisfaction amongst aged care staff: exploring the influence of person-centred care provision", International Psychogeriatrics, Vol. 23, pp. 1205-1212, doi: 10.1017/S1041610211000159.

Edvardsson, D., Sandman, P.O. and Borell, L. (2014), "Implementing national guidelines for personcentred care of people with dementia in residential aged care: effects on perceived personcenteredness, staff strain, and stress of conscience”, International Psychogeriatrics, Vol. 26, pp. 1171-1179, doi: 10.1017/S1041610214000258.

Ekman, I., Swedberg, K., Taft, C., Lindseth, A., Norberg, A., Brink, E., Carlsson, J., Dahlin-Ivanoff, S., Johansson, I.L., Kjellgren, K., Lidén, E., Öhlén, J., Olsson, L.E., Rosén, H., Rydmark, M. and Stibrant Sunnerhagen, K. (2011), "Person-centred care-ready for prime time", European Journal of Cardiovascular Nursing, Vol. 10, pp. 248-251, doi: 10.1016/j.ejcnurse.2011.06.008.

Ekman, I., Hedman, H., Swedberg, K. and Wallengren Gustafsson, C. (2015), "Commentary: Swedish initiative on person-centred care", BMJ, Vol. 350, p. h160, doi: 10.1136/bmj.h160.

European Committee for Standardization, CEN (2020), "CEN/TC450 - Patient involvement in personcentred care", EN17398:2020, available at: https://standards.cen.eu/dyn/www/f?p=204:7:0*:.: FSP_ORG_ID:2151116\&cs=1D44A19AFA1BBECA019313BDB1377FF73.

European Council on Foreign Relations, ECFR (2020), "Health sovereignty: how to build a resilient European response to pandemics", available at: https://ecfr.eu/publication/health_sovereignty_ how_to_build_a_resilient_european_response_to_pandemics/.

Gyllensten, H., Koinberg, I., Carlström, E., Olsson, L.E. and Hansson Olofsson, E. (2019), "Economic evaluation of a person-centred care intervention in head and neck oncology: results from a randomized controlled trial", Support Care Cancer, Vol. 27, pp. 1825-1834, doi: 10.1007/s00520018-4436-2.

Härter, M., Dirmaier, J., Scholl, I., Donner-Banzhoff, N., Dierks, M.L., Eich, W., Müller, H., Klemperer, D., Koch, K. and Bieber, C. (2017), "The long way of implementing patient-centred care and shared decision making in Germany", Qualität im Gesundheitswesen, Vol. 123-124, pp. 46-51, doi: 10.1016/j.zefq.2017.05.006.

International Alliance of Patients' Organizations, IAPO (2020), "The global voice for patient-centred healthcare", available at: https://www.iapo.org.uk.

Kaminska, M.E., Druga, E., Stupele, L. and Malinar, A. (2021), "Changing the healthcare financing paradigm: domestic actors and international organizations in the agenda setting for diffusion of social health insurance in post-communist Central and Eastern Europe”, Social Policy and Administration, Published Online. doi: 10.1111/spol.12724.

Lodge, A.C., Kaufman, L. and Stevens Manser, S. (2017), "Barriers to implementing person-centered recovery planning in public mental health organizations in Texas: results from nine focus groups", Administration and Policy in Mental Health, Vol. 44, pp. 413-429, doi: 10.1007/s10488-016-0732-7.

Lydahl, D. (2017), "Visible persons, invisible work? Exploring articulation work in the implementation of person-centred care on a hospital ward", Sociologisk Forskning, Vol. 54, pp. 163-179, available at: http://du.diva-portal.org/smash/get/diva2:1143769/FULLTEXT01.pdf.

McCance, T., Gribben, B., McCormack, B. and Laird, E. (2013), "Promoting person-centred practice within acute care: the impact of culture and context on a facilitated practice development programme", International Practice Development Journal, Vol. 3, pp. 1-17, available at: http:// www.fons.org/library/journal.aspx.

McCormack, B., Karlsson, B., Dewing, J. and Lerdal, A. (2010), "Exploring person-centredness: a qualitative meta-synthesis of four studies", Scandinavian Journal of Caring Sciences, Vol. 24, pp. 620-634, doi: 10.1111/j.1471-6712.2010.00814.x. 
Moore, L., Britten, N., Lydahl, D., Naldemirci, Ö., Elam, M. and Wolf, A. (2017), "Barriers and facilitators to the implementation of person-centred care in different healthcare contexts", Scandinavian Journal of Caring Sciences, Vol. 31, pp. 662-673, doi: 10.1111/scs.12376.

Naldemirci, Ö., Wolf, A., Elam, M., Doris Lydahl, D., Moore, L. and Britten, N. (2017), "Deliberate and emergent strategies for implementing person-centred care: a qualitative interview study with researchers, professionals and patients", BMC Health Service Research, Vol. 17, p. 527, doi: 10. 1186/s12913-017-2470-2.

OECD. European Observatory on Health Systems and Policies (2017), State of Health in the EU, Country Health Profile 2017, available at: https://ec.europa.eu/health/sites/health/files/state/ docs/english.pdf.

Oppert, M.L., O’Keeffe, V.J. and Duong, D. (2018), "Knowledge, facilitators and barriers to the practice of person-centred care in aged care workers: a qualitative study", Geriatric Nursing, Vol. 39, pp. 683-688, doi: 10.1016/j.gerinurse.2018.05.004.

Or, Z., Cases, C., Lisac, M., Vrangbeak, K., Winblad, U. and Bevan, G. (2010), "Are health problems systemic? Politics of access and choice under Beveridge and Bismarck systems", Health Economics, Policy and Law, Vol. 5, pp. 269-293, doi: 10.1017/S1744133110000034.

Pirhonen, L., Hansson Olofsson, E., Fors, A., Ekman, I. and Bolin, K. (2017), "Effects of person-centred care on health outcomes-A randomized controlled trial in patients with acute coronary syndrome”, Health Policy, Vol. 121, pp. 169-179, doi: 10.1016/j.healthpol.2016.12.003.

Pirhonen, L., Bolin, K., Hansson Olofsson, E., Fors, A., Inger Ekman, I., Swedberg, K. and Gyllensten, H. (2019), "Person-centred care in patients with acute coronary syndrome: cost-effectiveness analysis alongside a randomised controlled trial", Pharmaco Economics Open, Vol. 3, pp. 495-504, doi: 10.1007/s41669-019-0126-3.

Polit, D. and Beck, C.T. (2017), Nursing Research: Generating and Assessing Evidence for Nursing Practice, Wolters Kluwer Health/Lippincott Williams and Wilkins, Philadelphia.

Ricoeur, P. (1992), Oneself as Another, The University of Chicago Press, Chicago.

Risberg, G., Hamberg, K. and Johansson, E. (2006), "Gender perspective in medicine: a vital part of medical scientific rationality. A useful model for comprehending structures and hierarchies within medical science”, BMC Medicine, Vol. 4, pp. 1-5, doi: 10.1186/1741-7015-4-20.

Røen, I., Kirkevold, Ø., Testad, I., Selbæk, G., Engedal, K. and Bergh, S. (2018), "Person-centered care in Norwegian nursing homes and its relation to organizational factors and staff characteristics: a cross-sectional survey", International Psychogeriatrics, Vol. 30, pp. 1279-1290, doi: 10.1017/ S1041610217002708.

Rosengren, K. (2016), "Person-centred care: a qualitative study on first line managers' experiences on its implementation”, Health Services Management Research, Vol. 29, pp. 42-49, doi: 10.1177/ 0951484816637748.

Rosengren, K., Danielsson, L., Jansson, I. and Wallengren Gustafsson, C. (2018), "Development of an academic course in person-centred care for students in higher education - teachers' perspectives", Education Research International, p. 9, 9854169, doi: 10.1155/2018/9854169.

Swedish Agency for Health and Care Services Analysis (2018a), "From recipient to co-creator. A knowledge base for a more person-centred health care, (Från mottagare till medskapare. Ett kunskapsunderlag för en mer personcentrerad hälso- och sjukvård), Vol. 8, available at: https:// www.vardanalys.se/rapporter/fran-mottagare-till-medskapare/.

Swedish Agency for Health and Care Services Analysis (2018b), "Implementation in healthcare. An overview of knowledge about decision levels and professional perspectives (Implementering i vården. En kunskapsöversikt om beslutsnivåer och professionsperspektiv)", available at: https://www.vardanalys.se/rapporter/implementering-i-varden/.

Swedish Code of Statutes 2017:30 (2017), "Hälso- och sjukvårdslagen (health and medical services act)”, (In Swedish), available at: https://www.riksdagen.se/sv/dokument-lagar/dokument/ svensk-forfattningssamling/halso-och-sjukvardslag-201730_sfs-2017-30. 
The University of Gothenburg Centre for Person-centred Care, GPCC (2020), "University of Gothenburg centre for person-centred care", available at: http://gpcc.gu.se/en.

Torbica, A., Tarricone, R. and Drummond, M. (2018), "Does the approach to economic evaluation in health care depend on culture, values, and institutional context?", European Journal of Health Economics, Vol. 19, pp. 769-774, doi: 10.1007/s10198-017-0943-1.

UN (2020), "Human rights", available at: https://www.un.org.

Vassbø, T.K., Kirkevold, M., Edvardsson, D., Sjogren, K., Lood, Q., Sandman, P.O. and Bergland, A. (2019), "Associations between job satisfaction, person-centredness, and ethically difficult situations in nursing homes-A cross-sectional study", Journal of Advanced Nursing, Vol. 75, pp. 979-988, doi: 10.1111/jan.13890.

Wranik, D. (2012), "Healthcare policy tools as determinants of health-system efficiency: evidence from the OECD", Health Economics, Policy and Law, Vol. 7, pp. 197-226, doi: 10.1017/ S1744133111000211.

\section{Further reading}

Dahlborg Lyckhage, E., Skyvell-Nilsson, M. and Pennbrant, S. (2015), "Prerequisites for personcentred care: as described by community care nurses", Clinical Nursing Studies, Vol. 3, pp. 5-13, doi: $10.5430 /$ cns.v3n1p5.

\section{Corresponding author}

Kristina Rosengren can be contacted at: kristina.rosengren@gu.se

For instructions on how to order reprints of this article, please visit our website: 